therapy was 6 years (range 2-9 years). Three patients had residual deformity of the knee joint and 4 patients had deformity at the wrist joint. The changes on wrist X-ray included lucency and thinning of the ulnar metaphysis, small ulnar epiphysis, deformation and impaired growth of the physeal cartilage leading to reduced distance between the epiphysis and metaphysis (Figure1 and 2). The knee radiograph showed subchondral flattening of femoral and tibial condyles with irregular articular margins.

Conclusions Bony dysplasia, deformation and impaired growth of ulnar and radial epiphyses, metaphyses and physes may be an expression of deferiprone related arthropathy in children with thalassemia major.

\section{ARTERIAL THROMBOSIS IN CHILDREN}

doi:10.1136/archdischild-2012-302724.0759

${ }^{1} \mathrm{~T}$ Tavladaki, ${ }^{2} \mathrm{E}$ Blevrakis, ${ }^{2} \mathrm{AM}$ Spanaki, ${ }^{2} \mathrm{E}$ Geromarkaki, ${ }^{2} \mathrm{E}$ Vasilaki, ${ }^{2} \mathrm{D}$ Fitrolaki, ${ }^{2} \mathrm{~S}$ llia, ${ }^{2} \mathrm{G}$ Briasoulis. 'University of Crete; ${ }^{2}$ University Hospital of Crete, Heraklion, Greece

Introduction Thrombophilia was initially attributed to inherited hypercoagulability state, in the same way as hemophilia, however by the time this term extended to include acquired cases as well. True idiopathic thrombosis is extremely rare in children. Multiple risk factors are often present in pediatric patients; indwelling catheter, inflammatory conditions, malignancy, immobilization, thrombophilia and congenital heart disease. The role of thrombophilia in determining the risk of arterial thrombotic events is less well defined.

Objectives This study aimed to collect the number of children hospitalized in PICU, suffering from arterial thrombosis and to reveal the possible etiological factors.

Methods The study was conducted from $1^{\text {st }}$ of January 2007 till $1^{\text {st }}$ of January 2012, comprising 436 children aged from 2 months to 17 years old. The patient's records were retrospectively evaluated.

Results

Abstract 759 Table 1 Patients

\begin{tabular}{|c|c|c|c|}
\hline patients & $\begin{array}{l}\text { Factor of } \\
\text { thrombophilia }\end{array}$ & $\begin{array}{l}\text { Other factor for } \\
\text { thrombosis }\end{array}$ & Area of thrombosis \\
\hline 4 years old male & Protein $\mathrm{C}$ deficiency & Femoral artery catheter & Femoral artery \\
\hline 17 months male & Factor VIII & infection & $\begin{array}{l}\text { Posterior cerebral } \\
\text { artery }\end{array}$ \\
\hline $31 / 2$ years female & G20210A & $\begin{array}{l}\text { Congenital heart } \\
\text { operation }\end{array}$ & Medial cerebral artery \\
\hline
\end{tabular}

Conclusion Arterial thromboses encountered in our PICU do not constitute a frequent diagnosis, however when exist can lead to great disability (stroke, limb loss ...) or even death. It also seems that a combination rather than a single factor play role in the formation of arterial thrombus in children.

\section{INFECTION IN CHILDREN WITH HEMOPHILIA (EXPERIENCE IN THE PAEDIATRIC HOSPITAL BATNA)}

doi:10.1136/archdischild-2012-302724.0760

SB Brahmi, H Zerguine, H Soltani, T Bendhib, F Karchi. CHU Benflis Touhami, Universite de Batna, Park Aforage, Algeria

Introduction Hemophilia; Constitutional most common coagulopathy with hemophilia $\mathrm{A}$ is 5 times more common than hemophilia B.

Serious not only about the risk of joint and muscle scars but also viral contamination in transfusions and the risk of post-traumatic infections.
Objectives To determine the frequency and severity of infections in children with hemophilia. Demonstrate the value of prophylaxis in the prevention of bleeding.

Materials and Methods Retrospective study on cases of children with hemophilia hospitalized for a period of 4.5 years (01-01-2007 to 31-07-2011). 26 patients with hemophilia complicated.

Results The incidence varies between $0.90 \%$ and $2.4 \%$.

The child with hemophilia may be hospitalized for all age groups with a maximum 10 -year entre 5 . Only $38.46 \%$ of our patients have a family history of hemophilia.

$61.54 \%$ have a severe form (factor VIII or IX $<1 \%$ ).

$38.88 \%$ were hospitalized for a hemarthrosis of the knee, the rest is represented by the other known locations bleeding in children with hemophilia.

14 of our patients developed infections (53.8\%), including 8 of knee arthritis, arthritis of the ankle, two subcutaneous abscesses, a dental abscess and 2 cases of hepatitis $B$.

Conclusion Our study confirmed the significant incidence of infection in children with hemophilia dominated by post-traumatic infections with two cases of hepatitis B which is to intensify the education of our children and the benefit of prophylactic to reduce the incidence of bleeding including the risk of infection.

\section{THROMBOELASTOGRAM AND THROMBIN GENERATION ASSAY FOR THE EVALUATION OF HEMOSTASIS IN NEWBORNS: EFFECTS OF PREMATURITY AND VITAMIN K}

doi:10.1136/archdischild-2012-302724.076

${ }^{1} \mathrm{~T}$ Ersoz, ${ }^{1} \mathrm{M}$ Yalaz, ${ }^{2} \mathrm{C}$ Balkan, ${ }^{1} \mathrm{O}$ Altun Koroglu, ${ }^{2} \mathrm{~K}$ Kavakli, ${ }^{1} \mathrm{~N}$ Kultursay. ${ }^{1}$ Neonatology; ${ }^{2}$ Pediatric Hematology, Ege University Faculty of Medicine, Izmir, Turkey

Background and Aims Thromboelastogram (TEG) gives information about the coagulation cascade showing the combined effects of coagulation factors and thrombocyte functions. Thrombin Generation Assay (TGA) measures the time dependent changes of thrombin concentration. Standard values for newborns do not exist for TGA and TEG. We aimed to evaluate the effects of prematurity and vitamin $\mathrm{K}$ on hemostatis by TEG and TGA in addition to conventional methods.

Methods Preterm $(n=16)$ and term $(n=36)$ infants who received routine vitamin $\mathrm{K}$ prophylaxis were evaluated with $\mathrm{pt}$, inr, ptt, fibrinogen, TEG and TGA measurements performed from cord blood and venous blood obtained on day 3 .

Results Cord blood pt, inr, ptt and fibrinogen values were similar in both groups. TEG- $R$ value was increased in preterm group showing delayed onset of coagulation compared to term group $(p=0.003)$. Other TEG and TGA measurements were similar in cord blood.

After vitamin $\mathrm{K}$ prophylaxis; pt and inr decreased, fibrinogen increased in preterm infants ( $\mathrm{p}$ values; 0.032, 0.01 and 0.009 , respectively). In term infants; ptt decreased, fibrinogen, TEG-R, TEG-MA and TGA-lag time increased after vitamin $\mathrm{K}$ ( $\mathrm{p}$ values; 0.034, 0.001, $<0.001,0.018,<0.001$ and 0.004 , respectively).

Conclusion In cord blood analyses; preterm infants didn't have a significant difference apart from a delay in coagulation. The cloth strength was increased in term infants after vitamin $\mathrm{K}$. The lack of such improvement in preterm infants may be attributable to immature hepatic functions of the preterms. Preliminary data for standard values of TEG and TGA were obtained.

\section{THE USE OF PENTAGLOBULIN IN NEONATAL IMMUNE HEMOLYTIC ANAEMIA}

doi:10.1136/archdischild-2012-302724.0762

HE Aqrabawi. Pediatrics, King Hussein Medical Center, Amman, Jordan 
Objective To evaluate the efficacy of pentaglobulin in reducing the rate of exchange transfusion among neonates with immune hemolytic anaemia.

Method An observational prospective study that was conducted over two year's period starting from January 2010 to January 2012. Pentaglobulin was given in a dose of $1 \mathrm{gm} / \mathrm{Kg} /$ day for all newborns with the following criteria: immune hemolytic anaemia; high or rising level of bilirubin approaching exchange transfusion. Phototherapy was used in conjunction with pentaglobulin.

Results The total number of newborns who received pentaglobulin over that period of time was 85 infants. None of them required exchange transfusion. Ten newborns required top up transfusion. The duration of phototherapy application ranged from 48 to 72 hours.

Conclusion The study shows that early use of pentaglobulin in immune hemolytic anaemia reduces the risk of exchange transfusion and the duration of phototherapy application. Further randomized controlled trials are needed to verify the results of our observations.

\section{VITAMIN B12 AND FOLATE DEFICIENCY IN HEALTHY NEONATES AND THEIR MOTHERS}

doi:10.1136/archdischild-2012-302724.0763

${ }^{1} \mathrm{~F}$ Guven, ${ }^{2} \mathrm{~A}$ Say, ${ }^{2} \mathrm{~N}$ Uygur Kulcu, ${ }^{2} \mathrm{~S}$ Nepesov, ${ }^{2} \mathrm{M}$ Inalhan, ${ }^{2} \mathrm{~S}$ Degirmenci, ${ }^{2} \mathrm{TA}$ Sabuncu. 'Zeynep Kamil Maternity and Childrens' Disease Training and Research State Hospital, Isparta; 'Zeynep Kamil Maternity and Childrens' Disease Training and Research State Hospital, Istanbul, Turkey

Background and Aim We aimed to determine the incidence of vitamin B12 and folate deficiency in healthy neonates and their mothers; to show the correlation between maternal and neonatal B12 and folate levels.

Method The study consisted of 99 healthy neonates and their mothers who gave birth in Zeynep Kamil Maternity and Children Training and Research Hospital, İstanbul. Hospital records were reviewed and blood samples were obtained from both mothers and their babies in the 24 hours after birth. Serum vitamin B12 and folate levels were measured. SPSS 15.0 package program was used for statistical analysis.

Results The mean values were as follows: in mothers serum vitamin B12 level 180.84 $\pm 58.81 \mathrm{pg} / \mathrm{dl}$ and folate level 17.61 \pm 20.61 $\mathrm{nmol} / \mathrm{L}$; in neonates vitamin B12: $320.43 \pm 187.48 \mathrm{pg} / \mathrm{dl}$ and folate: $26.05 \pm 34.45 \mathrm{nmol} / \mathrm{L}$. There was significant correlation between maternal and neonatal folate levels but a slight correlation between maternal and neonatal B12 levels. $97 \%$ of mothers and $25.3 \%$ of neonates had B12 deficiency when the threshold level is defined as $300 \mathrm{pg} / \mathrm{ml}$ for mothers and $200 \mathrm{pg} / \mathrm{dl}$ for neonates.

Conclusion Due to high vitamin B12 deficiency rate in mothers a universal B12 vitamin screening program and preventative measures of B12 deficiency in pregnant women can reduce the potential complications of vitamin B12 deficiency in mothers and their siblings.

\section{A STUDY ON THE OUTCOME OF DIRECT COOMBS TEST (DCT) POSITIVE NEONATES}

doi:10.1136/archdischild-2012-302724.0764

KM Upatissa, J Greenaway, S Mahadevan-Bava. Paediatrics, Russells Hall Hospital, Dudley, UK

The management and follow up of neonates with DCT + differ from one centre to another. At RHH, guidelines recommend twice weekly FBC and Bilirubin in the first 2weeks, and review at 4-6weeks.

We retrospectively reviewed $52 \mathrm{DCT}+$ neonates born at $\mathrm{RHH}$ between May 2008 and June 2009 to assess their outcome and to evaluate the need to review the current guideline. We divided the sample into three groups. Group 1: Rh isoimmunisation due to $\mathrm{RhD}$ (39/52), 2: other $\mathrm{Rh}$ and non $\mathrm{Rh}$ alloimmunization (6/52) and 3: with $\mathrm{ABO}$ incompatibility $(7 / 52)$.

In group $1,38 / 39$ mothers received anti-D prophylaxis(RAADP). $20 / 39$ had weakly positive and $19 / 39$ had moderately DCT+. None of these neonates developed anaemia or prolonged jaundice.

In group $2(n=6), 3 / 6$ were strongly DCT + and $2 / 3$ developed jaundice $<24$ hours requiring phototherapy. $3 / 6$ showed moderately DCT + and 2 required phototherapy in the first week. At 2 weeks $4 / 6$ developed anaemia but did not warrant transfusion.

In group 3(n=7), 6 showed moderate DCT + and 1 weakly DCT+. $5 / 7$ in group 3 received phototherapy in the first week. 5/7 in group 2 developed prolonged jaundice. $1 / 7$ at 2 weeks showed anaemia.

We conclude that

1. Neonates born to mothers who received RAPPD do not show significant post delivery haemolysis and may not require close monitoring

2. Those with non RhD alloimmunisation and $A B O$ incompatibility require monitoring for haemolysis at 2 weeks and review at 6 weeks

3. Although small number in our study, strong positive DCT warrants close monitoring in the first 24 hours of age.

\section{LINEAR GROWTH AND CIRCULATING IGF-I CONCENTRATIONS IN CHILDREN WITH IRON DEFICIENCY ANEMIA AFTER TREATMENT}

doi:10.1136/archdischild-2012-302724.0765

A Soliman, M Eldabbagh, A Adel, A Sabt. Pediatrics, Hamad Medical Center, Doha, Oatar

Objective To assess linear growth of patients with Fe deficiency anemia (IDA) before and after in relation to their hematologic parameters and IGF-I concentration before and after treatment with iron.

Methods Forty children (aged $17.2+/-12.4$ ) months with iron deficiency anemia were studied with 40 healthy normal agematched children (controls). Patients were treated with iron syrup or drops to supply $6 \mathrm{mg} / \mathrm{kg} /$ day. Growth (weight, length and headcircumference) and hematological parameters were measured and IGF-I concentrations measured before and 3 and 6 months after treatment.

Results Growth parameters (weight, length and head-circumference) and hematological parameters were studied for 6 months after iron therapy. At presentation, patients with IDA had low $\mathrm{Hb}(8.2$ $+/-1.2 \mathrm{~g} / \mathrm{dl})$, hematocrit $(29+/-2.8)$, MCV $(61.5+/-8.1)$, and $\mathrm{MCH}(19+/-3.2)$ which improved significantly after treatment to $(11.2+/-1 \mathrm{~g} / \mathrm{dl}, 70.6+/-6.8,23.4+/-2.9$ and $18.9+/-5$ respectively). Before treatment children with iron deficiency they had length standard deviation score (LSDS) $=-1.2+/-1$, annualized growth velocity $(\mathrm{GV})=7.5+/-2.2$, GV SDS $=-1.42+/-0.6$ and $\mathrm{BMI}$ $=13.5+/-1.2$. After 6 months their LSDS $=-0.6+/--0.9$, annualized GV $=13.2+/-4.4 \mathrm{~cm} /$ year, GVSDS $=1.7+/-0.5$, and $\mathrm{BMI}=14.2$ $+/-1.1)$. Circulating IGF-I increased significantly after treatment $(52+/-18.8 \mathrm{ng} / \mathrm{ml})$ vs before treatment $(26.5+/-4.2 \mathrm{ng} / \mathrm{ml})$.

\section{A REVIEW OF TOLERATION OF PNUEMOCYSTIS CARINII PNEUMONITIS (PCP) PROPHYLAXIS TREATMENT IN CHILDREN WITH ACUTE LYMPHOBLASTIC LEUKAEMIA}

doi:10.1136/archdischild-2012-302724.0766

PM O'Hare, A Moody, T Zerb, D Lancaster. Paediatric Oncology, Royal Marsden Hospital, London, UK

Background and Aims According to the UKALL2003 protocol, co-trimoxazole should be used as first line therapy to prevent PCP 